\title{
Congenital Cytomegalovirus Infection: Cranial Imaging Signs
}

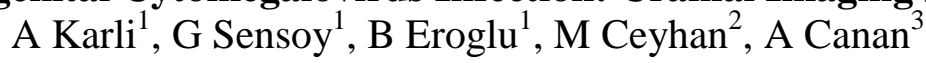

\section{İmage and Diagnosis}

\section{Clinical Data}

A twenty day-old male infant was referred to our hospital with hydrocephalus. It was reported that a 21 -year-old unbooked at $39^{\text {th }}$ weeks of gestation mother, delivered the baby by cesarian section because of prolonged labor. In his physical examination was $3100 \mathrm{~g}$ $\left(50^{\text {th }}\right.$ percentile $)$, length $51 \mathrm{~cm}\left(50^{\text {th }}\right.$ percentile $)$, head circumference $33,5 \mathrm{~cm}\left(<3^{\text {th }}\right.$ percentile $)$. No hepato-splenomegaly, jaundice, petechial rash and purpura were observed. Ohthalmologic examination and auditory brainstem responses were normal. Blood analysis showed: White blood cell count $9700 \mathrm{~mm}^{3}(\mathrm{~N}: 3400-9500)$, hemoglobin 14,2 g/dl (N: 11-14.5) and platelet count $178,000 \mathrm{~mm}^{3}(\mathrm{~N}: 150,0000-450,000)$. Liver and renal function tests were within normal levels. Serological tests for congenital infections asked. In lateral cranium graphy and transfontanellar ultrasound, intracranial calcification and ventricular dilatation were reported, respectively (Figure 1). Brain computed tomography revealed pathological findings consistent with ventriculomegaly and calcification surrounded both lateral ventricles (Figure 2).

Keywords: CMV, hydrocephalus, infant

From: ' Ondokuz Mayis University Faculty of Medicine, Department of Pediatric Infectious Diseases, Samsun, Turkey, ${ }^{2}$ Ondokuz Mayis University, Faculty of Medicine Department of Radiology, Samsun, Turkey, and ${ }^{3}$ Ondokuz Mayis University Faculty of Medicine Department of Neonatology, Samsun, Turkey.

Correspondence: Dr A Karli, Ondokuz Mayis University Faculty of Medicine, Department of Pediatric Infectious Diseases Samsun, Turkey. E-mail: drarzukarli@yahoo.com 


\section{What is the diagnosis?}

\section{Answer to Image and Diagnosis}

\section{Diagnosis}

Congenital Cytomegalovirus Infection

Serum specific Cytomegalovirus (CMV) immunoglobulin (Ig) levels (IgG and IgM) were consistent with a primary infection. Other serological tests included toxoplasma, rubella and herpes virus were negative. Polymerase chain reaction (PCR) CMV DNA was found positive with a high ratio in the urine and blood. The peripheral blood quantitative CMV DNA PCR 10200 copies/ml. Maternal serum specific CMV IgG was positive. Intravenous ganciclovir $(10 \mathrm{mg} / \mathrm{kg} /$ day) was administered. It was planned to place a shunt on the patient who was being followed for head circumference. However, the family discharged the patient on the fourteenth day of the treatment to complete the treatment on location but did not come back for follow-ups.

\section{Comment}

CMV is an important cause of congenital infections. Congenital CMV infection (cCMV) causes neurodevelopmental permanent damage such as mental retardation, cerebral palsy, hearing loss and chorioretinitis in newborns. It is the most common cause of nonhereditary sensorineural hearing loss $(1,2)$. The effect of cCMV on health is little known by both the society and health personnel. The most effective protection for the prevention of fetal infection is educating the mother and pregnancy follow-up. It is thought that using ganciclovir limits the neurodevelopmental damage caused by cCMV infection (3). Thus, infants with cCMV infection should be determined, they should be assessed for antiviral 
Karli et al

treatment and they should be closely followed for neurological development and hearing screening. 


\section{REFERENCES}

1. Dollard SC, Grosse SD, Ross DS. New estimates of the prevalence of neurological and sensory sequelae and mortality associated with congenital cytomegalovirus infection. Rev Med Virol 2007; 17: 355-63.

2. Fowler KB, Boppana SB. Congenital cytomegalovirus (CMV) infection and hearing deficit. J Clin Virol 2006; 35: 226-31.

3. Swanson EC, Schleiss MR. Congenital cytomegalovirus infection: new prospect for prevention and therapy. Pediatr Clin North Am 2013; 60: 335-49. 


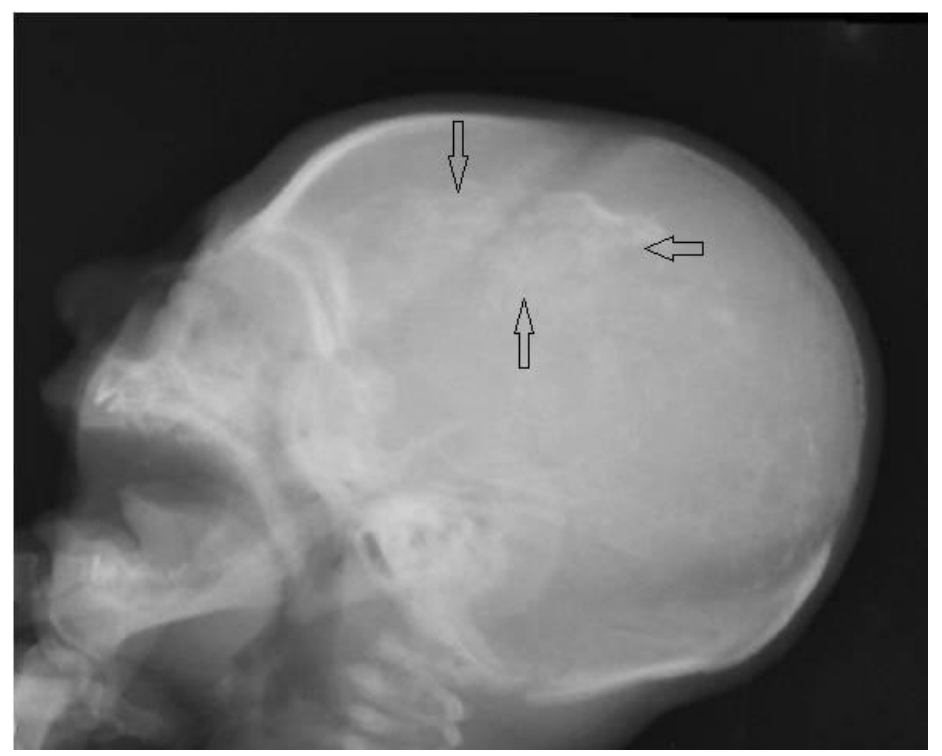

Figure 1: The large calcific areas in the lateral cranium graphy

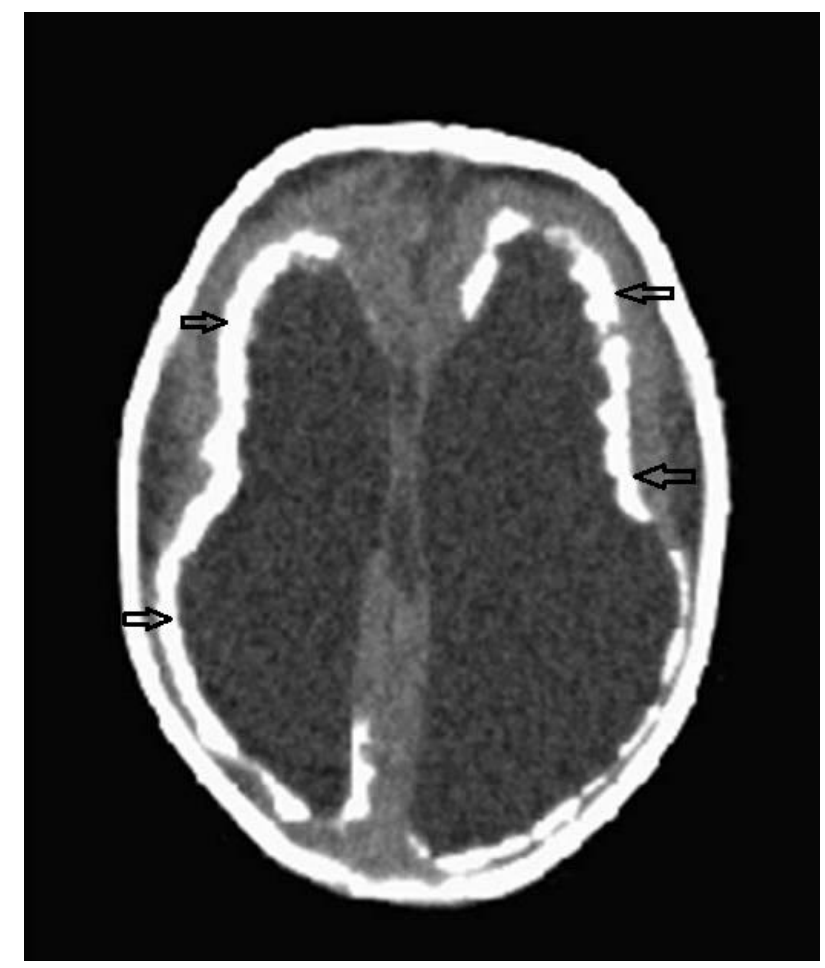

Figure 2: Brain BT pointed the dilatation and calcification in both lateral ventricles 